exacerbations are poorly recorded suggesting COPD reviews are poorly conducted/documented. This may lead to failure to increase maintenance regimens. Longitudinal assessment noted rapid increase in MRCD recording after this became remunerable under QOF. Exacerbation frequency recording should be incorporated into QOF. This dataset sets a baseline from which effectiveness of the National Clinical Strategy can be measured.

${ }^{1}$ The Patient Outcomes \& Information Service (POINTS) is provided by GlaxoSmithKline as a service to medicine and is delivered on behalf of GlaxoSmithKline by Quintiles.

\section{S110 EMPLOYMENT HISTORIES OF PEOPLE WITH ASTHMA IN THE 1958 BIRTH COHORT}

doi:10.1136/thx.2010.150946.11

${ }^{1} \mathrm{R}$ Ghosh, ${ }^{1} \mathrm{D}$ Jarvis, ${ }^{2} \mathrm{D}$ Strachan, ${ }^{1} \mathrm{P}$ Cullinan. ${ }^{1} / \mathrm{mperial}$ College, London, UK; ${ }^{2}$ St. Georges, University of London, London, UK

Reports suggest that people with asthma experience frequent job changes, perhaps to avoid working environments that worsen their asthma. The aim of this analysis is to compare the number of periods of unemployment and jobs from early to mid adult life in people with and without asthma. Due to the differing employment histories of men and women the analyses are presented stratified by sex.

Methods Participants from the 1958 birth cohort who provided a full occupational history and information on asthma at ages 16 and 42 $(n=9856)$ were included. Employment was defined as a period spent in a job, in child/family care or in full-time education. Unemployment was defined as a period out of employment due to unemployment, sickness/disability or other unspecified reasons. Non-parametric methods were used to determine differences in (1) ever being unemployed (2) number of unemployment periods and (3) number of jobs (all to the age of 42 years) by asthma status (childhood asthma, adult onset asthma and the reporting of 'ever asthma' at age 42).

Results $45.8 \%$ of men and $39.5 \%$ of women had ever been unemployed by age 42 . The median number of jobs by age 42 was 6 (range $1-23$ ) and of unemployment periods was 0 (range $0-15$ ).

1. In women, adult onset asthma and reporting 'ever asthma' at 42 were significantly associated with ever being unemployed ( $p=0.026, p<0.000$ respectively), but no associations were seen in men.

2. Childhood asthma and reporting 'ever asthma' at 42 were not associated with the number of unemployment periods in either men or women. However, adult onset asthma was associated with increased number of unemployment periods in women $(p=0.033)$, but not men.

3. Differences in number of jobs by asthma status are tabulated. Conclusions In a cohort of adults born in 1958, women with adult onset asthma had an increased risk of experiencing unemployment, an increased number of unemployment periods and an increased number of jobs by age 42 years. In men, there was limited evidence that their asthma influenced their employment experience. It is not known whether these associations are seen in more recent cohorts.

\begin{tabular}{|c|c|c|c|c|c|c|}
\hline Median number of: & $\mathbf{n}$ & $\begin{array}{l}\text { Jobs MEN } \\
\text { (IOR) }\end{array}$ & $\begin{array}{l}\text { p Value } \\
\text { (Mann- } \\
\text { Whitney) }\end{array}$ & $\mathbf{n}$ & $\begin{array}{l}\text { Jobs } \\
\text { WOMEN } \\
\text { (IOR) }\end{array}$ & $\begin{array}{l}\text { p Value } \\
\text { (Mann- } \\
\text { Whitney) }\end{array}$ \\
\hline Childhood asthma NO & 2972 & 5 (3 to 7$)$ & $p=0.310$ & 3436 & 6 (4 to 9 ) & $p=0.513$ \\
\hline Childhood asthma YES & 487 & $5(3$ to 7$)$ & & 352 & 6 (4 to 9 ) & \\
\hline Adult onset asthma NO & 3549 & 5 (3 to 7$)$ & $\mathrm{p}=0.583$ & 3852 & 6 (4 to 9 ) & $p=0.005$ \\
\hline Adult onset asthma YES & 250 & 5 (3 to 8$)$ & & 424 & 7 (4 to 9 ) & \\
\hline Ever asthma by $42 \mathrm{NO}$ & 4248 & 5 (3 to 7$)$ & $p=0.029$ & 4469 & 6 (4 to 9 ) & $p<0.000$ \\
\hline Ever asthma by 42 YES & 480 & 5 (3 to 8$)$ & & 623 & 7 (4 to 9 ) & \\
\hline
\end{tabular}

Funding This work was funded by Asthma UK, RG PhD funded by the COLT Foundation. S111 ASTHMA, PUBERTY AND BMI IN THE 1958 BRITISH BIRTH
COHORT

doi:10.1136/thx.2010.150946.12

D L Jarvis, L Gnatiuc, R B Newson. Imperial College London, London, UK

Studies suggest asthma is associated with body mass index (BMI), pubertal development and hormonal status. We used data collected at ages 7, 11, 16 and 33 from the 1958 British Birth Cohort to explore the association of asthma with BMI and pubertal development. Wheeze was considered present at age 7,11 or 16 if participant's mothers reported 'ever attacks of asthma or wheezy bronchitis' and, at age 33, if participants reported 'wheezing or whistling in the chest' in the last year. Age of menarche was reported at age 16 . The association at each age of wheeze with BMI $(<18.5,18.5<25,25+)$ and with age of menarche $(<12,13-14$ years, $16+)$ was assessed in logistic regression models adjusted for parental asthma, father's social class, birth order and smoking (age 33 only). At age 7, 11 and 16, being overweight was associated with wheeze, an association that was stronger and more significant in girls than in boys. Wheeze at age 33 was associated with being overweight at age 33 in both men and women, but there was no consistent evidence that being overweight in childhood was associated with wheeze at the age of 33. Among 4524 girls with information $15.4 \%$ had reached menarche by age 12 , and $2.2 \%$ had not reached menarche by age 16 . The prevalence of being overweight at age 11 in the early and late menarche groups was $20.6 \%$ and $1.25 \%$ respectively, and the prevalence of being underweight at the age of 16 was $3.7 \%$ and $47.0 \%$. Early menarche was associated with wheeze at age 11 ( $\mathrm{OR}=1.57,95 \% \mathrm{CI} 1.19$ to 2.09$)$ even in 11-year-old girls with normal BMI. Late, but not early menarche was associated with wheeze at age $16(\mathrm{OR}=2.09,95 \% \mathrm{CI} 1.17$ to 3.73$)$. Neither early nor late menarche was associated with wheeze at age 33 years. At each follow-up of the 1958 birth cohort, wheeze was associated with being overweight in females. Although girls with early menarche were more overweight in childhood, and experienced more wheeze at age 11 , there was no evidence that early menarche was associated with wheeze at the age of 33 years.

\section{S112 THE NATURAL HISTORY OF WHEEZE FROM BIRTH TO ADULT LIFE: A COHORT STUDY}

doi:10.1136/thx.2010.150946.13

${ }^{1} \mathrm{M} L$ Burr, ${ }^{1} \mathrm{~F} \mathrm{D}$ J Dunstan, ${ }^{2} \mathrm{~S}$ Hand, ${ }^{3} \mathrm{~K}$ P Jones, ${ }^{3} \mathrm{~S}$ Rolf. ${ }^{1}$ Cardiff University, Cardiff, UK; ${ }^{2}$ Prince Charles Hospital, Merthyr Tydfil, UK; ${ }^{3}$ UWIC, Cardiff, UK

Introduction and objectives Wheeze is a common symptom at all ages. Its natural history from birth to adulthood was studied in a birth cohort of individuals at high risk of atopic illness. The objective was to ascertain factors associated with wheeze at different ages, distinguishing between wheeze that occurred at successive time points (persistent wheeze) and wheeze newly occurring (incident wheeze). Methods 497 infants were selected antenatally as having a firstdegree relative with a history of asthma, hay fever or eczema. During their first year and at 7 years the children were examined, symptoms were recorded, skin prick tests performed and serum $\operatorname{IgE}$ measured. At 15 and 23 years further questionnaires were completed and (at 23) blood and skin tests performed.

Results Information was obtained on 483 individuals at 1 year, 453 at seven, 363 at 15 and 304 at 23. The prevalence of wheeze was fairly constant over time (around $30 \%$ ), remission being balanced by incidence over each interval. Wheeze at 1 year predicted wheeze at ages seven and 15 , and at seven it predicted wheeze at 15 and 23 , but it was associated with different factors at different times and according to whether it was persistent or incident. In infancy it was related to non-atopic factors such as infection, maternal smoking and breastfeeding (protective). Persistent wheeze to age 15 was 
related to respiratory infections in infancy and to atopy. Incident wheeze from one to 7 years was strongly associated with atopy, while late-onset wheeze was related to rhino conjunctivitis, smoking and (marginally) body mass.

Conclusions Advances in the understanding and prevention of wheeze may be assisted by directing attention to maternal smoking, breastfeeding and respiratory infections in infancy, atopy in childhood, rhino conjunctivitis in adolescence, and smoking and perhaps obesity in adult life.

\section{S113 THE EFFECT OF SMALL AIRWAYS DISEASE AND EMPHYSEMA ON THE ASSOCIATION BETWEEN SMOKING AND LUNG FUNCTION, AND BRONCHODILATOR RESPONSE}

doi:10.1136/thx.2010.150946.14

${ }^{1} \mathrm{~B}$ D Patel, ${ }^{2} \mathrm{H} O$ Coxson, ${ }^{3} \mathrm{P}$ G Camp, ${ }^{4} \mathrm{~S}$ G Pillai, ${ }^{5} \mathrm{~A}$ G Agusti, ${ }^{6} \mathrm{P} \mathrm{M}$ Calverley, ${ }^{7} \mathrm{C}$ F Donner, ${ }^{8} \mathrm{~B}$ J Make, ${ }^{2} \mathrm{~N}$ L Müller, ${ }^{9} \mathrm{~S}$ I Rennard, ${ }^{10} \mathrm{~J}$ Vestbo, ${ }^{11} \mathrm{E}$ F Wouters, ${ }^{4} \mathrm{~W}$ H Anderson, ${ }^{3} \mathrm{P} D$ Paré, ${ }^{3} \mathrm{R} D$ Levy, ${ }^{12} \mathrm{E}$ K Silverman, ${ }^{13} \mathrm{D}$ A Lomas. ${ }^{1}$ Department of Respiratory Medicine, Royal Devon and Exeter Hospital, Exeter, UK; '2Department of Radiology, University of British Columbia, Vancover, Canada; ${ }^{3}$ Division of Respiratory Medicine, University of British Columbia, Vancouver, Canada; ${ }^{4}$ GlaxoSmithKline, Raleigh, USA; ${ }^{5}$ Thorax Institute, Hospital Clinic Barcelona, Mallorca, Spain; ${ }^{6}$ University of Liverpool, Liverpool, UK; ' Division of Pulmonary Disease, S. Maugeri Foundation, Veruno, Italy; ${ }^{8}$ National Jewish Medical and Research Centre, Denver, USA; ${ }^{9}$ University of Nebraska, Omaha, USA; ${ }^{10}$ North West Lung Centre, Wythenshawe Hospital, Manchester, UK; ${ }^{11}$ Department of Respiratory Medicine, University Hospital Maastricht, Maastricht, Netherlands; ${ }^{12}$ Brigham and Women's Hospital and Harvard Medical School, Boston, USA; ${ }^{13}$ Department of Medicine, University of Cambridge, Cambridge, UK

Introduction and objectives The airflow limitation of COPD results from small airway disease and emphysema. These phenotypes are likely to have independent genetic risk factors. It is not known if the heterogeneity of COPD accounts for the relatively weak association between pack-years smoked and forced expiratory volume in $1 \mathrm{~s}$ $\left(\mathrm{FEV}_{1}\right)$ seen within smoking populations, or bronchodilator response (BDR). This study aimed to assess the effect of these phenotypes on the association between smoking and $\mathrm{FEV}_{1}$ and on BDR.

Method The international COPD genetics network is a multi-centre study aimed at identifying genes that predispose to COPD, in which high resolution computed tomography (HRCT) was used to quantify components of the COPD phenotype: (i) emphysema detected by radiologists (RE), (ii) emphysema assessed as per cent lowattenuation area (\%LAA) and (iii) airway wall thickness (AWT) for airways with an internal perimeter of $10 \mathrm{~mm}$ (Pi10), $20 \mathrm{~mm}$ (Pi20), and average per cent wall area (WA\%). They were then assessed for their effect on the association between smoking and lung function $\left(\mathrm{FEV}_{1} \%\right.$ predicted $\left.\left(\mathrm{FEV}_{1} \%\right)\right)$, and on $\mathrm{BDR}$.

Results RE data were available for 1159 individuals, 745 had complete data for Pi10, Pi20, AWT\% and \%LAA. The association between packyears smoked and $\mathrm{FEV}_{1} \%$ was greater in those without $(\mathrm{r}=-0.41)$, compared to those with, RE $(\mathrm{r}=-0.12, \mathrm{p}<0.001$ for difference in effect). AWT and RE correlated with $\mathrm{FEV}_{1} \%$ but had different relationships with smoking; AWT was positively associated with packyears but there was no relationship between RE severity and pack-years smoked. RE, \%LAA and AWT made independent contributions to $\mathrm{FEV}_{1} \%$. Post-bronchodilator increase in $\mathrm{FEV}_{1}$ was inversely associated with severity of RE (Abstract S113 Table 1), even after adjustment for pre-bronchodilator $\mathrm{FEV}_{1}(\mathrm{p}<0.01)$. BDR was also inversely associated with \%LAA ( $p=0.02$, and $p \leq 0.05$ adjusted for baseline $\mathrm{FEV}_{1}$ ).

\section{Abstract S113 Table 1}

\begin{tabular}{lllll}
\hline Severity of RE & Mild (5-25\%) & Moderate (25-50\%) & Severe (>50\%) & p (trend) \\
\hline Number & 228 & 185 & 266 & - \\
BDR, FEV1 (mls) & $171.3 \pm 188.2$ & $134.4 \pm 174.7$ & $100.2 \pm 129.6$ & $\leq 0.0001$ \\
\hline
\end{tabular}

Conclusion The AWT component of COPD, but not the severity of $\mathrm{RE}$, increases with pack-years smoked, and the association between pack-years and FEV1\% is greatest in those with an airway predominant phenotype. This suggests different gene-smoking interactions between phenotypes. RE and \%LAA independently contribute to FEV1\% and therefore measure different components of emphysema, however both were inversely associated with BDR.

\section{Measurements in patients with chronic cough S114 A DOUBLE BLIND, PLACEBO CONTROLLED, RANDOMISED, STUDY TO ASSESS THE EFFECTS OF PLACEBO, CODEINE AND TALNETANT, ON CITRIC ACID COUGH THRESHOLD IN HEALTHY SUBJECTS}

doi:10.1136/thx.2010.150946.15

S Khalid, A Woodcock, B Haumann, P Ventresca, S J Langley, J A Smith. University Hospital of South Manchester, Manchester, UK

Background Previous studies have shown a reduction in cough response to inhaled citric acid after blocking NK1, NK2 and also NK3 receptors in guinea pigs. NK3 receptor may be more relevant to study the role of tachykinins in cough due to their greater specificity for its agonist neurokinin B. We studied a specific NK3 receptor antagonist Talnetant to determine the effect on the human cough reflex sensitivity to citric acid in healthy individuals. Oral codeine and placebo were included as comparators.

Methods Double-blind, randomised, placebo-controlled, 4-period cross-over study in non-smoking healthy adult volunteers. A total of 28 subjects $(12 \mathrm{M}, 16 \mathrm{~F})$ with mean age of 33 years (SD 10.5, range 22-55) were studied. Each subject received A. matched placebos; B. Talnetant $200 \mathrm{mg}$; C. Talnetant $25 \mathrm{mg}$; D. Codeine $60 \mathrm{mg}$, in a double blind double dummy manner. Subjects were randomly assigned to one of four treatment sequences (ABCD, BCDA, DCAB, BDCA). Each study period was $24 \mathrm{~h}$ with citric-acid challenges performed at 2, 6, 10 and $24 \mathrm{~h}$ post dose and a 7 day washout period between treatments. Results There was no significant difference in logC5 Citric acid between Talnetant $25 \mathrm{mgs}, 200 \mathrm{mgs}$ and placebo at any time point (see Abstract S114 Figure 1). The 'positive' control codeine had a non-significant trend for improvement in $\log \mathrm{C} 5$ compared to placebo (all confidence intervals contained unity). Talantent was adequately absorbed with sustained blood levels at time points designed to coincide with the cough challenges.

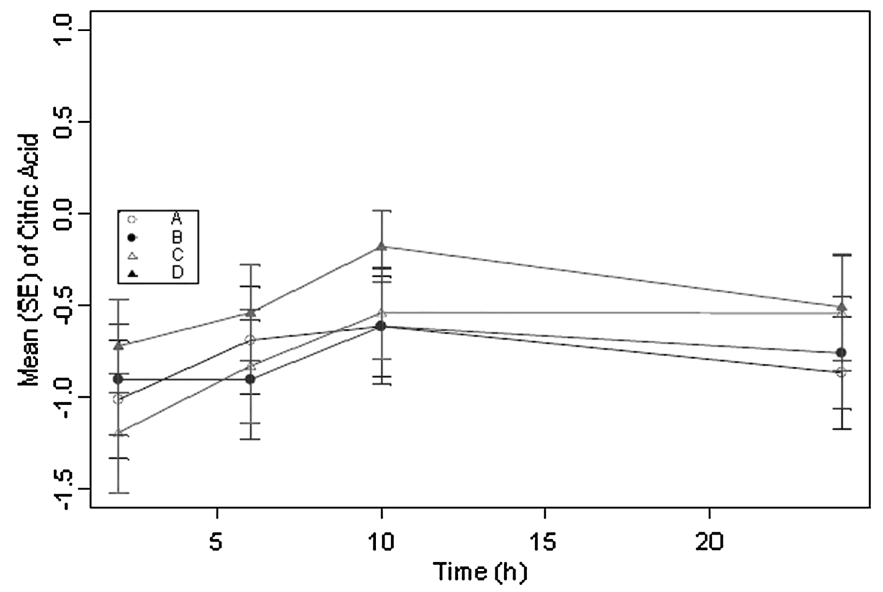

Abstract S114 Figure 1 